\title{
Comprehensive Study of Valuable Lipophilic Phytochemicals in Wheat Bran
}

\author{
Pepijn Prinsen, ${ }^{\dagger}$ Ana Gutiérrez, ${ }^{\dagger}$ Craig B. Faulds, ${ }^{\ddagger}, \S$ and José C. del Río ${ }^{\dagger} * *$ \\ ${ }^{\dagger}$ Instituto de Recursos Naturales y Agrobiología de Sevilla, CSIC, P.O. Box 1052, E- 41080 Seville, Spain \\ ${ }^{\ddagger}$ Aix Marseille Université, POLYTECH Marseille, UMR 1163 Biotechnologie des Champignons Filamenteux, 163 avenue de Luminy, \\ 13288 Marseille cedex 09, France \\ ${ }^{\S}$ INRA, UMR 1163 Biotechnologie des Champignons Filamenteux, 163 avenue de Luminy, 13288 Marseille cedex 09, France
}

\begin{abstract}
Wheat bran, the major side-stream generated in the milling of wheat grains in the production of white flour, contains significant quantities of carbohydrate and proteins. While not interfering with flour utilization, the bran could be considered as an important feedstock within a biorefinery concept. Wheat bran also contains some amounts of lipids that can be used as a source of valuable phytochemicals. Gas chromatography and mass spectrometry analysis of the lipid composition of destarched wheat bran demonstrated that the predominant lipids found in wheat bran were free fatty acids (ca. $40 \%$ of total lipids), followed by acylglycerols (40\%). Additionally, important amounts of alkylresorcinols (13\% of total lipids) and steroid compounds (hydrocarbons, ketones, free sterols, sterol glycosides, sterol esters, and sterol ferulates) (7\% of total lipids) were also present among the lipids of wheat bran. The use of wheat bran as a valuable source of phytochemicals of interest in the context of a wheat bran biorefinery is discussed.
\end{abstract}

KEYWORDS: wheat bran, lipids, alkylresorcinols, steroids, triglycerides

\section{INTRODUCTION}

Wheat (Triticum spp.) is among the most extensively cultivated crop in the world, and is the most widely grown and consumed cereal by humans. ${ }^{1}$ Whole-grain wheat is composed of $10-14 \%$ bran, $2.5-3.0 \%$ germ, and $80-85 \%$ endosperm. ${ }^{2}$ Wheat bran is the hard outer layer of a wheat grain and consists of the combined aleurone and pericarp. Wheat bran is produced in enormous quantities as a major byproduct of the milling process for the production of white wheat flour, with an annual estimated production of 90 million tons. ${ }^{3}$

Nowadays, wheat bran is mainly used as a low value ingredient for both human and animal feed. ${ }^{4}$ However, due to the enormous quantities produced in the milling industry and its specific properties, wheat bran has also been considered to have an enormous potential as a valuable and versatile feedstock for future biorefineries ${ }^{3}$ or as a value-added stream of existing milling facilities. The development of such biorefinery systems utilizing agro-industrial side-streams or byproducts are essential for ensuring the sustainable supply of food, feed, chemicals, materials, goods, fuels, and energy in the future. Commercially produced wheat bran contains relatively low amounts of cellulose (16\%) and lignin (6.6\%), but presents important amounts of glucuronoarabinoxylans (38\%), proteins (25\%), and starch (9\%). ${ }^{3,5}$ However, wheat bran also contains significant amounts (up to 4\%) of lipids that can also be used as a source of valuable phytochemicals. ${ }^{3}$ It is known that phytochemicals present in grains have the potential to reduce some diseases, including cardiovascular diseases, ${ }^{6}$ diabetes, ${ }^{7}$ and cancer. ${ }^{8,9}$ Some of the mentioned health benefits may be attributed to the antioxidant activity of phenolic compounds such as ferulic acid, other polyphenols (lignans, anthocyanins and alkylresorcinols), carotenoids, and vitamin E. In particular, wheat bran has been widely recognized as a cancer preventive agent, although the mechanism of the protection is not yet fully understood. ${ }^{9}$ The lipophilic extractives of wheat bran are known to be cytotoxic, 9,10 and in particular alkylresorcinols have been found to exert higher cytotoxic effects on cancer cells. ${ }^{11}$

However, and despite its high significance, there are only limited studies reporting the complete and detailed chemical composition of lipids in wheat bran. Alkylresorcinols have been among the most widely reported lipid compounds in wheat bran, ${ }^{9,11-14}$ although other lipid constituents, such as fatty acids and sterols, have also been reported., ${ }^{9,12}$ In this work, we performed a comprehensive characterization of the lipophilic compounds occurring in wheat bran by the use of gas chromatography (GC) and gas chromatography-mass spectrometry (GC-MS), according to the method previously described. ${ }^{15}$ This study can provide significant further knowledge about the composition of lipids of wheat bran, which can be regarded as a valuable source of active phytochemicals.

\section{MATERIALS AND METHODS}

Samples. The wheat bran used for this study consisted of a commercial destarched sample obtained from Agro-industrie Recherchés et Developments (Pomacle, France). The sample was stored at room temperature in an opaque sealed container, with a moisture content of $8 \%$, until further processing. Additional information regarding the bulk composition of this sample has been previously published. ${ }^{5}$ The wheat bran sample was subsequently air-dried and knife-milled (Janke and Kunkel, Analysenmühle), and the lipophilic compounds extracted with acetone for $8 \mathrm{~h}$ in a Soxhlet apparatus. The acetone extracts were evaporated to dryness, and resuspended in

Received: October 23, 2013

Revised: January 20, 2014

Accepted: January 22, 2014

Published: January 22, 2014 
chloroform for chromatographic analysis of the lipid fraction. The acetone-extracted sample was then extracted with hot water $(100 \mathrm{~mL}$, $3 \mathrm{~h}$ at $100{ }^{\circ} \mathrm{C}$ ) to determine the water-soluble material. Klason lignin content was estimated as the residue after sulphuric acid hydrolysis of the pre-extracted material, corrected for ash and protein content, according to the TAPPI method T222 om- $88 .{ }^{16}$ The acid-soluble lignin was determined, after the insoluble lignin was filtered off (Duran filter crucible 4; nominal pore size max. 10-16 $\mu \mathrm{m}$ ), by UV-spectroscopic determination at $205 \mathrm{~nm}$ wavelength using $110 \mathrm{~L} \mathrm{~cm}^{-1} \mathrm{~g}^{-1}$ as the extinction coefficient. Holocellulose was isolated from the pre-extracted fibers by delignification for $4 \mathrm{~h}$ using the acid chlorite method. ${ }^{17}$ The $\alpha$-cellulose content was determined by removing the hemicelluloses from the holocellulose by alkali extraction. ${ }^{17}$ Ash content was estimated as the residue after $6 \mathrm{~h}$ of heating at $575{ }^{\circ} \mathrm{C}$ according to the TAPPI method T211 om-02. ${ }^{16}$ Three replicates were used for each sample.

\section{Table 1. Abundance of the Main Constituents} (\% Dry-Weight) of Wheat Bran

\begin{tabular}{|c|c|}
\hline constituent & content $^{a}$ \\
\hline water-soluble extractives & $2.4 \pm 0.1$ \\
\hline lipids & $2.0 \pm 0.1$ \\
\hline Klason lignin ${ }^{b}$ & $12.1 \pm 0.8$ \\
\hline acid-soluble lignin & $8.5 \pm 1.0$ \\
\hline carbohydrates & $64.0 \pm 1.0$ \\
\hline$(\alpha$-cellulose $)$ & $(30 \pm 1.0)$ \\
\hline proteins $^{c}$ & $9.9 \pm 1.0$ \\
\hline ash & $1.1 \pm 0.1$ \\
\hline
\end{tabular}

${ }^{a}$ Average of three replicates. ${ }^{b}$ Corrected for proteins and ash. ${ }^{c}$ Determined indirectly by subtracting the other components to $100 \%$.
GC and GC-MS Analyses. The lipophilic extractives $(0.8 \mathrm{mg})$ were silylated with $0.250 \mathrm{~mL}$ bis(trimethylsilyl)trifluoroacetamide (BSTFA, from Supelco) in the presence of $0.050 \mathrm{~mL}$ pyridine at $70{ }^{\circ} \mathrm{C}$ for $2 \mathrm{~h}$ before GC and GC-MS analyses. An HP 5890 gas chromatograph (Hewlett-Packard, Hoofddorp, Netherlands) equipped with a split-splitless injector and a flame ionization detector (FID) was used for GC analyses. The injector and the detector temperatures were set at 300 and $350{ }^{\circ} \mathrm{C}$, respectively. Samples were injected in the splitless mode at a concentration of $7.5 \mathrm{mg} / \mathrm{mL}$. Helium was used as the carrier gas. The capillary column used was a high temperature, polyimide coated fused silica tubing DB5-HT (5 m x $0.25 \mathrm{~mm}$ I.D., $0.1 \mu \mathrm{m}$ film thickness; J\&W Scientific). The oven was temperatureprogrammed from $100{ }^{\circ} \mathrm{C}(1 \mathrm{~min})$ to $350{ }^{\circ} \mathrm{C}(3 \mathrm{~min})$ at $15^{\circ} \mathrm{C} \mathrm{min}^{-1}$. Peaks were quantified by area, and a mixture of different standards, such as octadecane (Sigma-Aldrich, 99\%), palmitic acid (Sigma-Aldrich, 99\%), sitosterol (Calbiochem, 98\%), cholesteryl stearate (Sigma-Aldrich, 99\%), sitosteryl 3 $\beta$-D-glucopyranoside (Matreya LLC, a mixture of three steryl glucosides of $98 \%$ purity, of which $56 \%$ correspond to sitosteryl glucoside) and triheptadecanoin (Sigma-Aldrich, 99\%), with a concentration range between 0.1 and $1 \mathrm{mg} / \mathrm{mL}$, was used to elaborate calibration curves. The correlation coefficient was higher than 0.99 in all cases. Quantification was obtained using response factors of the same or similar compounds (in the case of alkylresorcinols, they were quantified against sitosterol). The data from the three replicates were averaged. In all cases, the standard deviations from replicates were below $10 \%$ of the mean values. The total amounts of the different lipid families were determined by adding up the amounts of their constituent compounds.

The GC-MS analyses were performed on a Varian Star 3400 gas chromatograph (Varian, Walnut Creek, CA) coupled with an ion-trap detector (Varian Saturn 400) equipped with a high-temperature capillary column (DB-5HT, $15 \mathrm{~m} \times 0.25 \mathrm{~mm}$ i.d., $0.1 \mu \mathrm{m}$ film

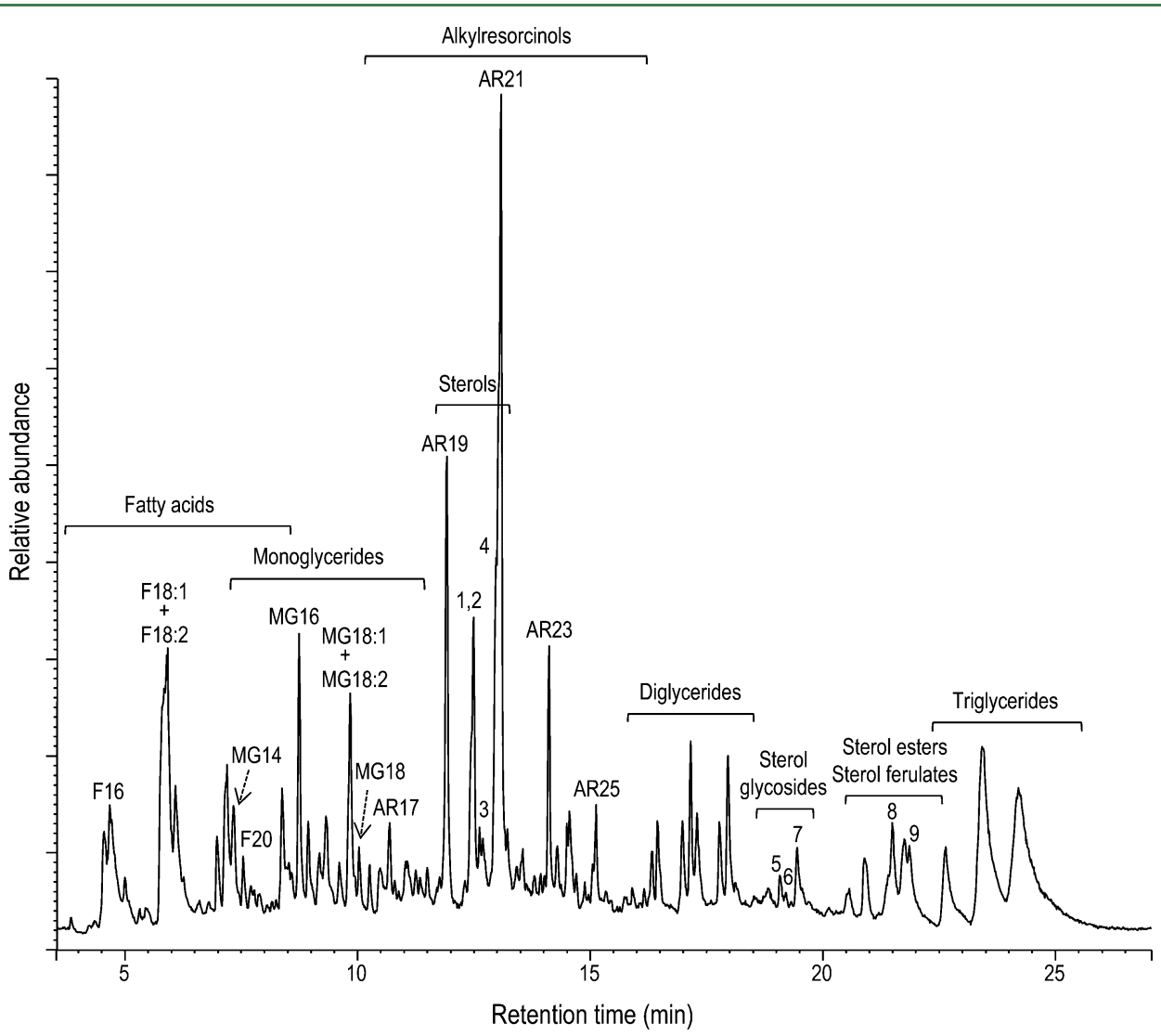

Figure 1. GC-MS chromatogram of the lipid extracts from wheat bran (as TMS-ether derivatives). $\mathrm{F}(n): n$-fatty acid series; MG( $n):$ monoglycerides; $\operatorname{AR}(n): n$-alkylresorcinols; $n$ denotes the total carbon atom number. Other compounds reflected are as follows: 1: campesterol; 2: campestanol; 3: stigmasterol; 4: sitosterol; 5: campesteryl $3 \beta$-D-glucopyranoside; 6: stigmasteryl $3 \beta$-D-glucopyranoside; 7: sitosteryl $3 \beta$-D-glucopyranoside; 8 : campestanyl ferulate; and 9: stigmastanyl ferulate. 
Table 2. Composition and Abundance (mg/kg Fiber, d.a.f.) of Main Lipids Identified in the Extracts of Wheat Bran

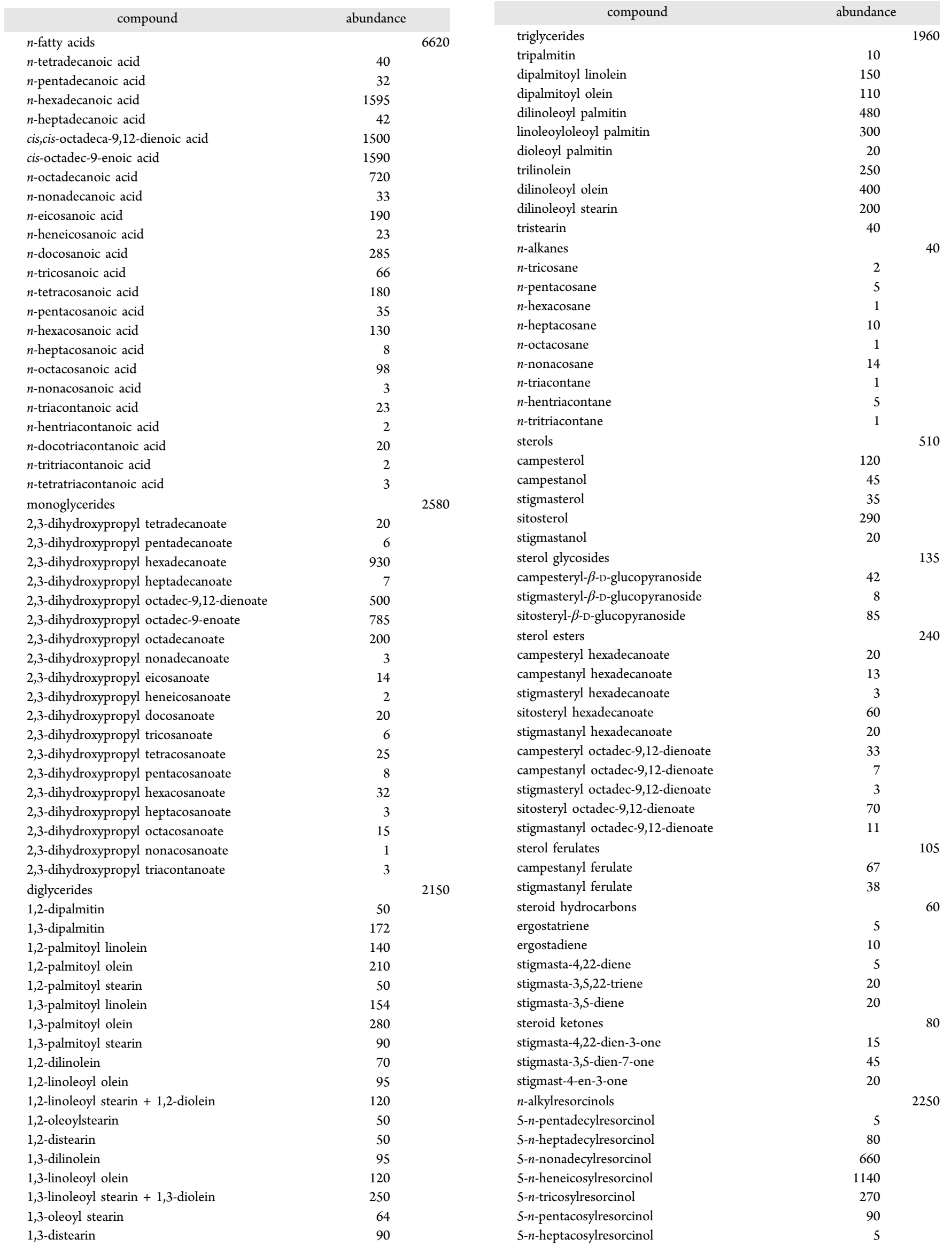


<smiles>CCCCCCCCCCCCCCCC(=O)O</smiles>

(I)<smiles>CCCCCCCC/C=C/CCCCCCCC(=O)O</smiles>

(II)<smiles>CCCCCC=CCC=CCCCCCCCC(=O)O</smiles>

(III)<smiles>CCCCCCCCCCCCCCCC(=O)OCC(O)CO</smiles><smiles>CCCCCCCC/C=C/CCCCCCCC(=O)OCC(O)CO</smiles><smiles>CCCCC/C=C/C/C=C/CCCCCCCC(=O)OCC(O)CO</smiles><smiles>CCCCCCCC/C=C/CCCCCCCC(=O)OC(CO)COC(=O)CCCCCCCCCCCCCCC</smiles><smiles>CCCCCCCC/C=C\CCCCCCCC(=O)OCC(O)COC(=O)CCCCCCCCCCCCCCC</smiles><smiles>CCCCC/C=C\C/C=C\CCCCCCCCC(=O)OC(COC(=O)CCCCCCC/C=C\C/C=C\CCCCC)COC(=O)CCCCCCCCCCCCCCC</smiles><smiles>CCCCCCCCCCCCCCCCCCCCCCCCCCCCCC</smiles>

(X)

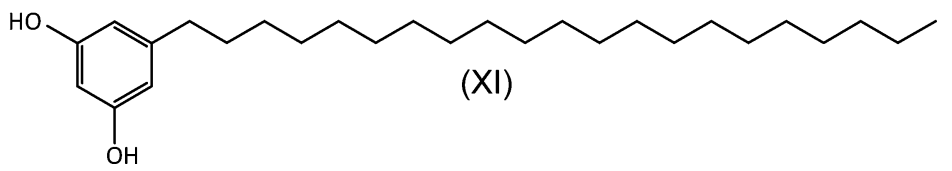

Figure 2. Structures representative of the main aliphatic lipophilic compounds identified in the extracts of wheat bran and referred in the text. (I) hexadecanoic (palmitic) acid; (II) 9-octadecenoic (oleic) acid; (III) 9,12-octadecadienoic (linoleic) acid; (IV) 2,3-dihydroxypropyl hexadecanoate (1-monopalmitin); (V) 2,3-dihydroxypropyl octadecenoate (1-monoolein); (VI) 2,3-dihydroxypropyl octadecadienoate (1-monolinolein); (VII) 1,2-palmitoyl olein; (VIII) 1,3-palmitoyl olein; (IX) dilineoylpalmitin; (X) n-nonacosane; and (XI) 5- $n$-heneicosylresorcinol.

thickness; J\&W Scientific). Helium was used as carrier gas at a rate of $2 \mathrm{~mL} / \mathrm{min}$. The samples, at concentrations of $2.5 \mathrm{mg} / \mathrm{mL}$, were injected with an autoinjector (Varian 8200) directly onto the column using a SPI (septum-equipped programmable injector) system. The temperature of the injector during the injection was $60{ }^{\circ} \mathrm{C}$, and $0.1 \mathrm{~min}$ after injection was programmed to $380^{\circ} \mathrm{C}$ at a rate of $200{ }^{\circ} \mathrm{C}$ $\mathrm{min}^{-1}$ and held for $10 \mathrm{~min}$. The oven was heated from $120^{\circ} \mathrm{C}$ $(1 \mathrm{~min})$ to $380{ }^{\circ} \mathrm{C}(5 \mathrm{~min})$ at $10^{\circ} \mathrm{C} \mathrm{min}^{-1}$. The temperature of the transfer line was set at $300{ }^{\circ} \mathrm{C}$. Compounds were identified by comparing their retention times and mass spectra with authentic standards, except for alkylresorcinols and sterol ferulates, which were tentatively identified by comparing their mass spectra with those reported in the literature. Single ion chromatographic profiles were used to estimate compound abundances when two peaks partially overlapped.

\section{RESULTS AND DISCUSSION}

Lipid Composition of Wheat Bran. The destarched wheat bran sample selected for this study is mostly composed of carbohydrates $(64.0 \%$ of the whole material, among which $30 \%$ corresponds to $\alpha$-cellulose), lignin (20.6\%), and proteins (9.9\%), as seen in Table 1. Minor amounts of water-soluble extractives (2.4\%), lipids (2.0\%), and ash (1.1\%) were also present in this sample. The detailed analysis of the chemical composition of the lipids was accomplished by GC and GC-MS (after preparation of the trimethylsilyl (TMS)-ether derivatives) according to the method previously described. ${ }^{15}$ The chromatographic conditions used for the analyses, by using short- and medium-length high-temperature capillary columns with thin 


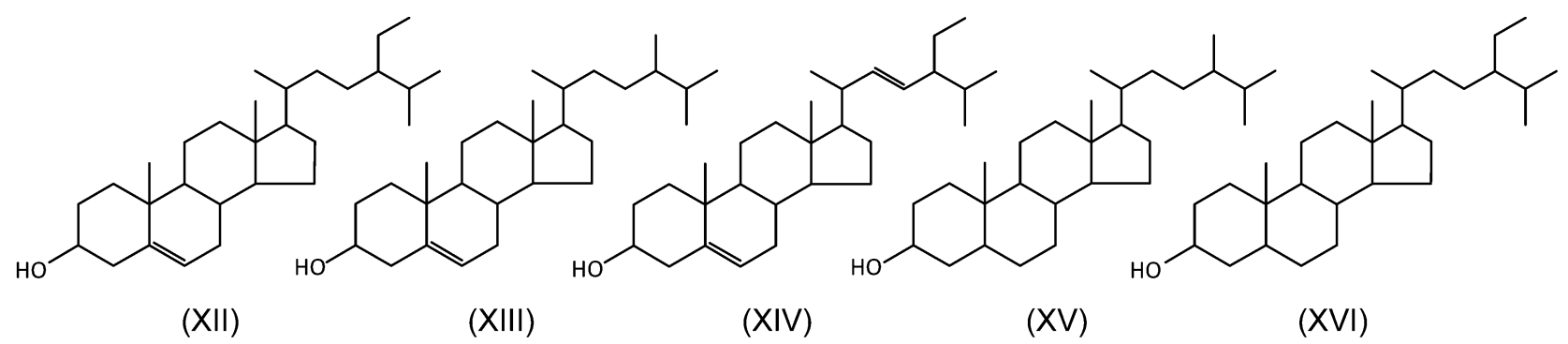<smiles>CCCCCC/C=C/C/C=C/CCCCCCCC(=O)OC1CCC2(C)C3=CCC4C5CCC(C(C)CCC(CC)C(C)C)C5(C)CCC4(C)C3CCC2(C)C1CCC(C)C(C)CCC(CC)C(C)C</smiles>

$(\mathrm{XVII})$

(XVIII)<smiles>CCC(CCC(C)C(C)C)C1CCC2C3CCC4CC(OC(=O)/C=C/c5ccc(O)c(OC)c5)CCC4(C)C3CCC12C</smiles>

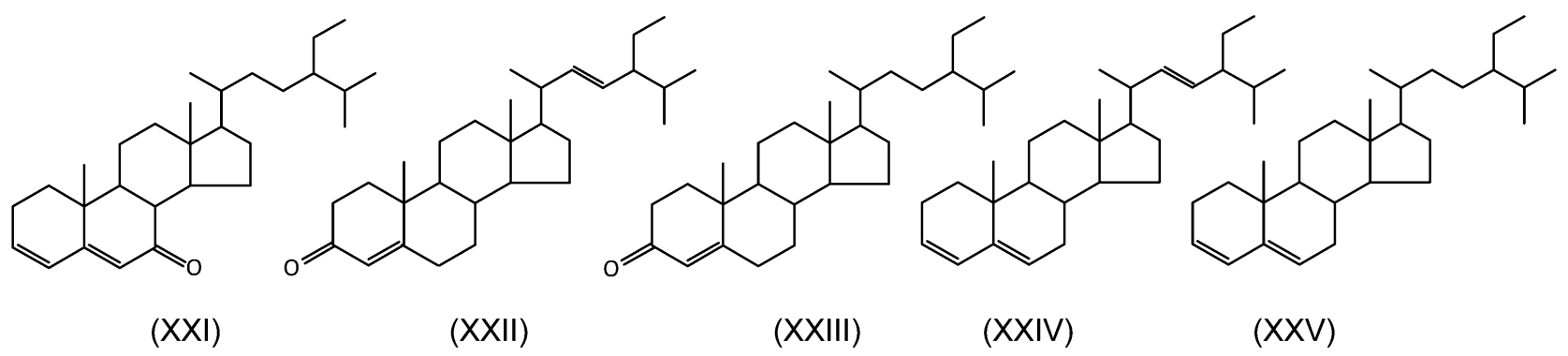

Figure 3. Structures of the main steroid compounds identified in wheat bran and referred in the text. (XII) sitosterol; (XIII) campesterol; (XIV) stigmasterol; (XV) campestanol; (XVI) stigmastanol; (XVII) sitosteryl 3 $\beta$-D-glucopyranoside; (XVIII) sitosteryl linoleate; (XIX) campestanyl ferulate; (XX) stigmastanyl ferulate; (XXI) stigmasta-3,5-dien-7-one; (XXII) stigmasta-4,22-dien-3-one; (XXIII) stigmasta-4-en-3-one; (XXIV) stigmasta-3,5,22-triene; and (XXV) stigmasta-3,5-diene.

films, allow for the elution of a wide range of compounds, from low molecular weight free fatty acids and sterols to intact high molecular weight lipids such as sterol esters, sterol glycosides, or triglycerides, that are usually biased in more standard GC conditions.

Figure 1 shows the GC-MS chromatogram of the lipids (as their TMS-ether derivatives) extracted from wheat bran. A large number of compounds were identified and quantified. The identities and abundances (mg/kg fiber, dry, ash-free basis) of the main lipid compounds identified in the extracts of wheat bran are listed in Table 2. Structures representative of the main lipid families identified in wheat bran, including aliphatic and steroid compounds, are shown in Figure 2 and Figure 3. The results demonstrated that the predominant lipids identified among the extracts of this wheat bran sample were series of free fatty acids, accounting for around $40 \%$ of all identified compounds, followed by series of acylglycerols ( $40 \%$ in total), that included mono-, di- and triglycerides. Important amounts of alkylresorcinols (13\% of all identified compounds) were also found among the lipids of wheat bran. Alkylresorcinols have been the most widely reported lipids in wheat bran., ${ }^{9,11-13}$ Steroid compounds (including hydrocarbons, ketones, free sterols, sterol glycosides, sterol esters, and sterol ferulates) were also present among the lipids of wheat bran in important amounts (7\% of all identified lipids). Only free sterols and sterol ferulates were previously reported among the lipids of wheat bran. ${ }^{9,12,18}$ Lower amounts of other aliphatic series such as $n$-alkanes, were also observed. The distributions of the main aliphatic series (fatty acids, $n$-alkanes, monoglycerides, and $n$-alkylresorcinols) are represented in the histograms of Figure 4.

Aliphatic Series. Free fatty acids $(6620 \mathrm{mg} / \mathrm{kg})$ were the most abundant family of identified lipids. The series of free fatty acids was found in the range from tetradecanoic acid $\left(\mathrm{C}_{14}\right)$ to tetratriacontanoic acid $\left(\mathrm{C}_{34}\right)$, with a predominance of the even 

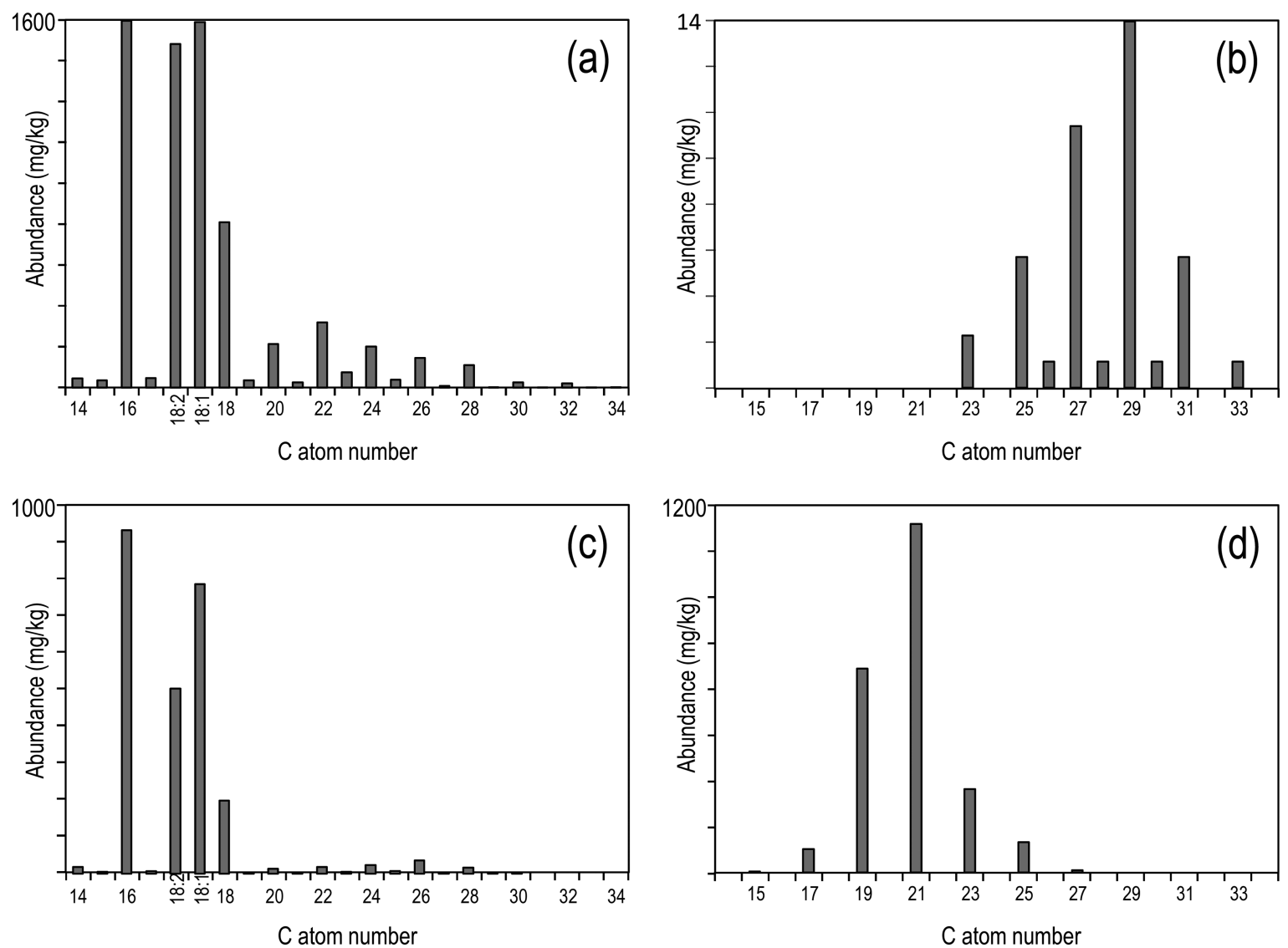

Figure 4. Distribution of the main aliphatic series identified in the extracts of wheat bran. (a) $n$-Fatty acids; (b) $n$-alkanes; (c) monoglycerides; and (d) $n$-alkylresorcinols. The histograms are scaled up to the abundance of the major compound in the series.

carbon atom number homologues. Hexadecanoic acid (palmitic acid, I) was the most abundant free fatty acid $(1595 \mathrm{mg} / \mathrm{kg})$, together with the unsaturated cis-9-octadecenoic acid (oleic acid, II) $(1590 \mathrm{mg} / \mathrm{kg})$ and cis,cis-9,12-octadecadienoic acid (linoleic acid, III) $(1500 \mathrm{mg} / \mathrm{kg})$. High amounts of the saturated octadecanoic acid (stearic acid) $(720 \mathrm{mg} / \mathrm{kg})$ were also found, while the rest of fatty acids were present in minor amounts. Despite the high abundance of fatty acids identified in wheat bran, a detailed analysis of their occurrence has not been performed so far, and there is a substantial gap in the information reported in the literature. The major free fatty acids previously reported in wheat bran were linolenic $\left(\mathrm{C}_{18: 3}\right)$ and linoleic $\left(\mathrm{C}_{18: 2}\right)$ acids, ${ }^{9}$ which substantially differ from our results.

Acylglycerols (including mono-, di-, and triglycerides) were also found among the lipids of wheat bran in important amounts, accounting for a total of $6490 \mathrm{mg} / \mathrm{kg}$, with monoglycerides being the predominant ones. However, and despite this abundance, the detailed analyses of their components have not been performed so far, and only the occurrence of the diglyceride dilinoleoylglycerol was previously reported. ${ }^{9}$ Monoglycerides in wheat bran accounted for $2580 \mathrm{mg} / \mathrm{kg}$, and were identified in the range from 2,3-dihydroxypropyl tetradecanoate $\left(\mathrm{C}_{14}\right)$ to 2,3-dihydroxypropyl triacontanoate $\left(\mathrm{C}_{30}\right)$, with a strong predominance of the even carbon atom number homologues. 1-Monopalmitin (IV) was the most abundant monoglyceride $(930 \mathrm{mg} / \mathrm{kg})$, followed by the unsaturated 1-monoolein ( $\mathbf{V}, 785 \mathrm{mg} / \mathrm{kg}$ ) and 1-monolinolein (VI, $500 \mathrm{mg} / \mathrm{kg}$ ), and the saturated 1 -monostearin $(200 \mathrm{mg} / \mathrm{kg})$. To our knowledge, this is the first time that the series of monoglycerides has been reported in wheat bran. The distribution of esterified fatty acids occurring as monoglycerides roughly matches that of the free fatty acids, as seen in the histograms of Figure 4. Diglycerides were also found in important amounts $(2150 \mathrm{mg} / \mathrm{kg})$ among the lipids in wheat bran. The most abundant diglycerides identified were 1,2-palmitoyl olein (VII) $(210 \mathrm{mg} / \mathrm{kg})$ and 1,3-palmitoyl olein (VIII) $(280 \mathrm{mg} / \mathrm{kg})$, with a predominance of the 1,3-isomers, as also occurs in other grasses. ${ }^{19,20}$ Palmitic and linoleic acids were the most important esterified fatty acids occurring as diglycerides, as also occurred in the case of monoglycerides. A previous work only identified dilineoylglycerol (although it did not report the substitution pattern), but these compounds are minor components in our study. Triglycerides were also identified in high amounts among the lipids of wheat bran, accounting for $1960 \mathrm{mg} / \mathrm{kg}$, (Table 2) and, although their occurrence was previously reported, ${ }^{9}$ this is the first time that the identification of individual triglycerides was achieved by GC-MS. Dilinoleoyl palmitin (IX) was the most abundant triglyceride in the wheat bran sample $(480 \mathrm{mg} / \mathrm{kg})$ followed by dilinoleoyl olein $(400 \mathrm{mg} / \mathrm{kg})$, linoleyloleyl palmitin $(300 \mathrm{mg} / \mathrm{kg})$, and trilinolein $(250 \mathrm{mg} / \mathrm{kg})$. Palmitic and linoleic acids were the most abundant esterified fatty acids present as triglycerides, as also occurred in the case of mono- and diglycerides.

A series of $n$-alkanes could also be identified among the lipids of wheat bran, although in lower amounts $(40 \mathrm{mg} / \mathrm{kg})$. The series of $n$-alkanes was found in the range from $n$-tricosane $\left(C_{23}\right)$ to $n$-tritriacontane $\left(\mathrm{C}_{31}\right)$, with a strong odd-over-even atom carbon number predominance. Nonacosane $(\mathbf{X})$ was the main compound of this series, accounting for $14 \mathrm{mg} / \mathrm{kg}$, followed by 

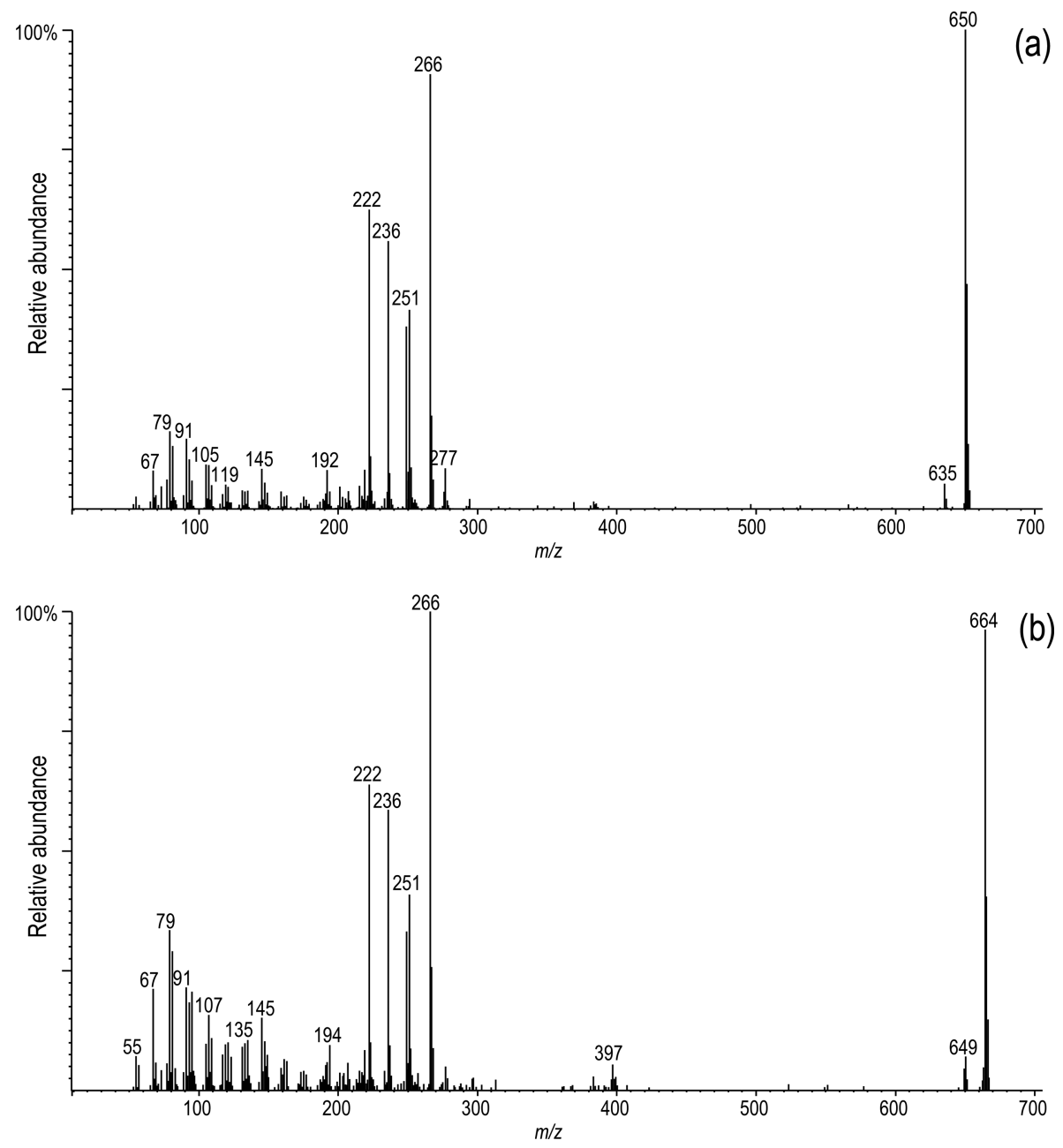

Figure 5. Mass spectra of (a) campestanyl ferulate, and (b) stigmastanyl ferulate, (as TMS ethers).

heptacosane $(10 \mathrm{mg} / \mathrm{kg})$. The rest of the alkanes were identified in very minor amounts.

Steroid Compounds. Different families of steroid compounds were identified among the lipids in wheat bran, including steroid hydrocarbons, steroid ketones, free sterols, sterol glycosides, sterol esters, and sterol ferulates. Free sterols, accounting for $510 \mathrm{mg} / \mathrm{kg}$, were the major family of steroid compounds present in wheat bran, with sitosterol (XII) occurring at the highest level (290 mg/kg), followed by campesterol (XIII) $(120 \mathrm{mg} / \mathrm{kg})$. In addition, lower amounts of stigmasterol (XIV) and the saturated campestanol (XV) and stigmastanol (XVI) were also identified. Sterols conjugated with carbohydrates forming sterol glycosides or with long chain fatty acids or ferulic acid forming sterol esters were also identified. Important amounts of sterol glycosides (135 mg/kg) were identified among the lipids of wheat bran by comparison with the mass spectra and relative retention times of authentic standards. ${ }^{21}$ As far as we know, this is the first time that sterol glycosides are reported as constituents of wheat bran lipids. Sitosteryl $3 \beta$-D-glucopyranoside (XVII) was the most predominant sterol glycoside in wheat bran $(85 \mathrm{mg} / \mathrm{kg})$ with lower amounts of campesteryl and stigmasteryl $3 \beta$-D-glucopyranosides, as usually observed in other grasses. ${ }^{19,20}$ Sterol esters of long chain fatty acids corresponding to campesterol, campestanol, stigmasterol, sitosterol, and stigmastanol esterified with different fatty acids were also found $(240 \mathrm{mg} / \mathrm{kg})$. Each sterol ester series identified showed two major peaks due to the esterification with the $\mathrm{C}_{16}$ (palmitic acid) and with the unsaturated linoleic acid.

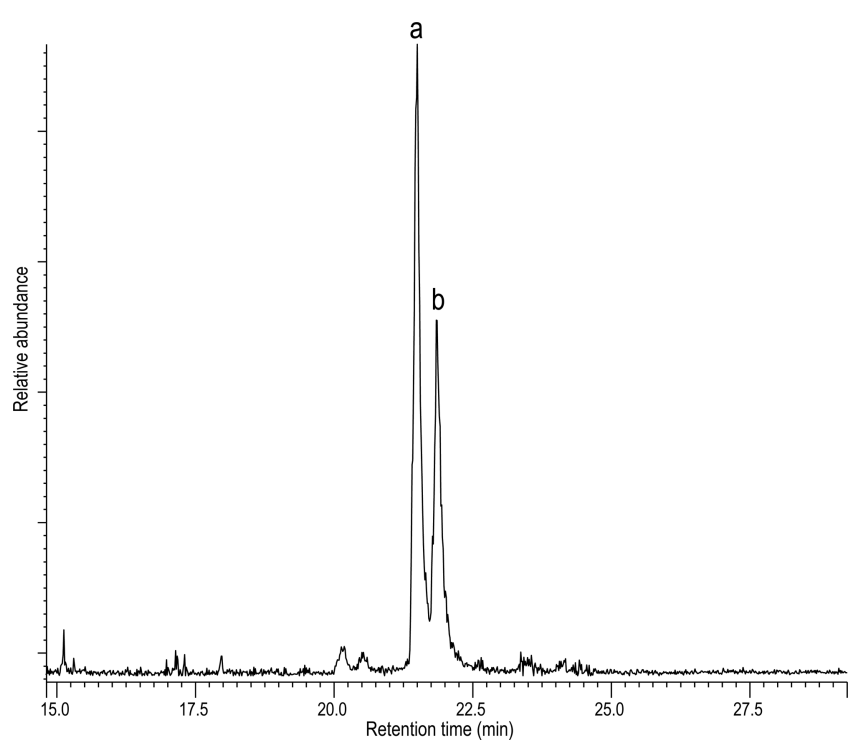

Figure 6. Single ion chromatogram $(m / z 266)$ showing the distribution of sterol ferulates (as TMS ethers) identified in the extracts of wheat bran. (a) Campestenyl ferulate; and (b) stigmastanyl ferulate.

Sitosteryl linoleate (XVIII) was the most predominant $(70 \mathrm{mg} / \mathrm{kg})$ sterol ester in wheat bran, followed by sitosteryl hexadecanoate $(60 \mathrm{mg} / \mathrm{kg})$, as also occurs in other cereals. ${ }^{22}$ 

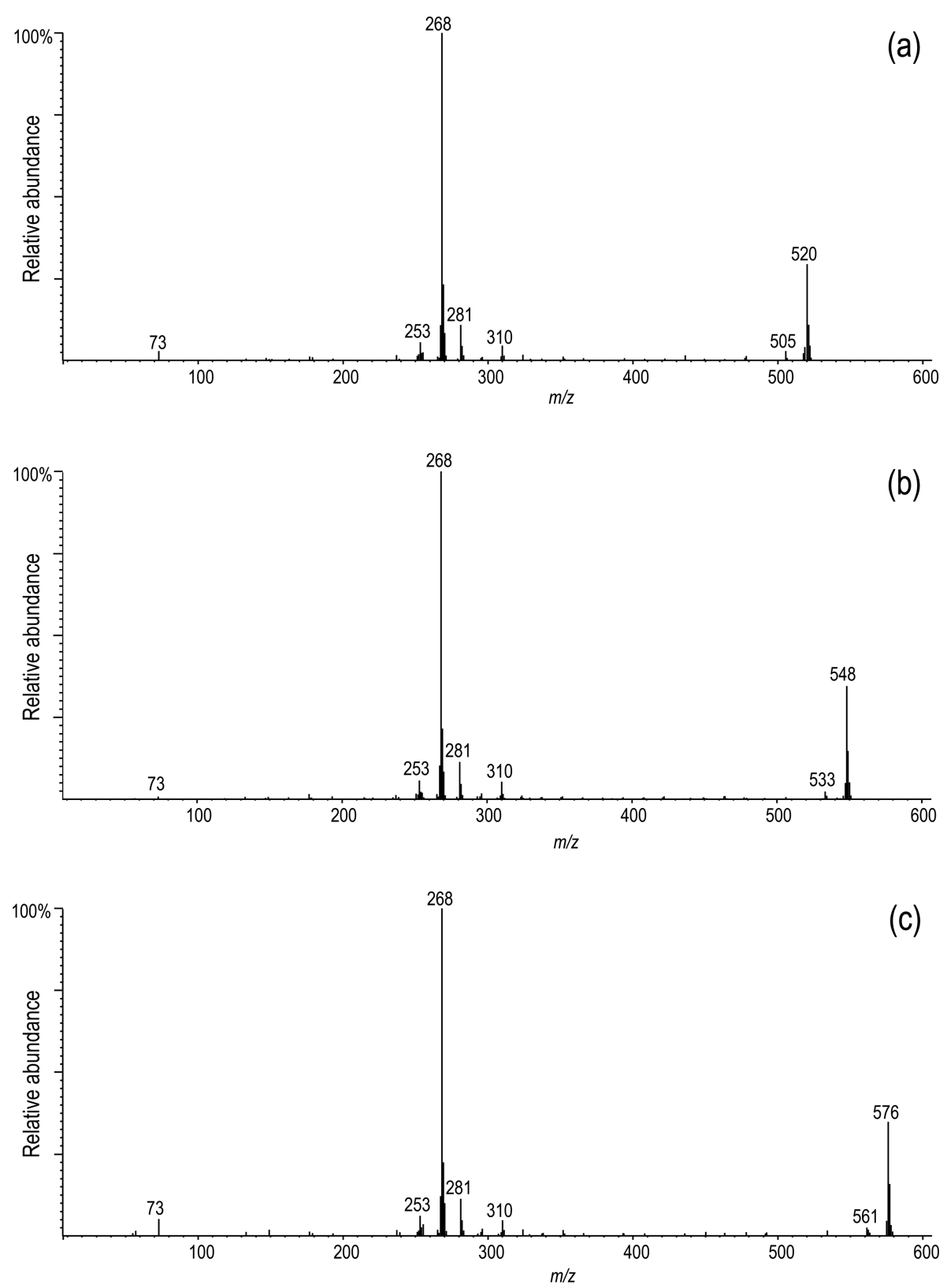

Figure 7. Mass spectra of selected alkylresorcinols (as TMS ethers): (a) 5- $n$-nonadecylresorcinol, (b) 5- $n$-heneicosylresorcinol, and (c) 5- $n$-tricosylresorcinol.

Sterol ferulates were also identified among the lipids of wheat bran $(105 \mathrm{mg} / \mathrm{kg})$, and consisted exclusively of the saturated campestanyl ferulate (XIX) and sitostanyl ferulate (XX). The identification of sterol ferulates was obtained from the mass spectra of their TMS ethers that show a characteristic base peak ion at $m / z 266$, typical of these molecules, together with the molecular ions at $m / z 650$ and $m / z 664$ for campestanyl and stigmastanyl ferulates, respectively. ${ }^{23}$ The mass spectra of these sterol ferulates are shown in Figure 5, whereas Figure 6 displays the single ion chromatogram $(m / z 266)$ showing the distribution of the series of sterol ferulates present among the lipids of wheat bran. The identification of these compounds is consistent with previous observations in several cereal bran oils. ${ }^{12}$ Different steroid ketones, namely stigmast-3,5-dien-7-one (XXI), stigmasta4,22-dien-3-one (XXII) and stigmast-4-en-3-one (XXIII), were also identified in lower amounts $(80 \mathrm{mg} / \mathrm{kg}$ ) among the lipids of wheat bran. Steroid hydrocarbons were also found, albeit in low amounts $(60 \mathrm{mg} / \mathrm{kg})$, and included stigmasta-3,5,22-triene (XXIV) and stigmasta-3,5-diene (XXV). The important amounts of steroid compounds present in wheat bran, and particularly the high content of free and conjugated sterols, makes wheat bran a good source of valuable phytosterols.

Alkylresorcinols. A series of 5- $n$-alkylresorcinos was identified among the lipids of wheat bran in important amounts $(2250 \mathrm{mg} / \mathrm{kg})$. The identification of 5 - $n$-alkylresorcinols was achieved from their mass spectra that show a base peak due to the McLafferty rearrangement at $m / z 268$, characteristic of these molecules. ${ }^{14,24}$ The mass spectra of three representative 5 - $n$-alkylresorcinols are shown in Figure 7, with the characteristic base peak at $\mathrm{m} / z 268$ and the molecular ions at $\mathrm{m} / z$ 520, $m / z 548$, and $m / z 576$ for the TMS ether derivatives of 5-n-nonadecyl-, 5-n-heneicosyl-, and 5-n-tricosylresorcinols, respectively. Figure 8 displays the single ion chromatogram $(m / z$ 268) showing the distribution of the series of 


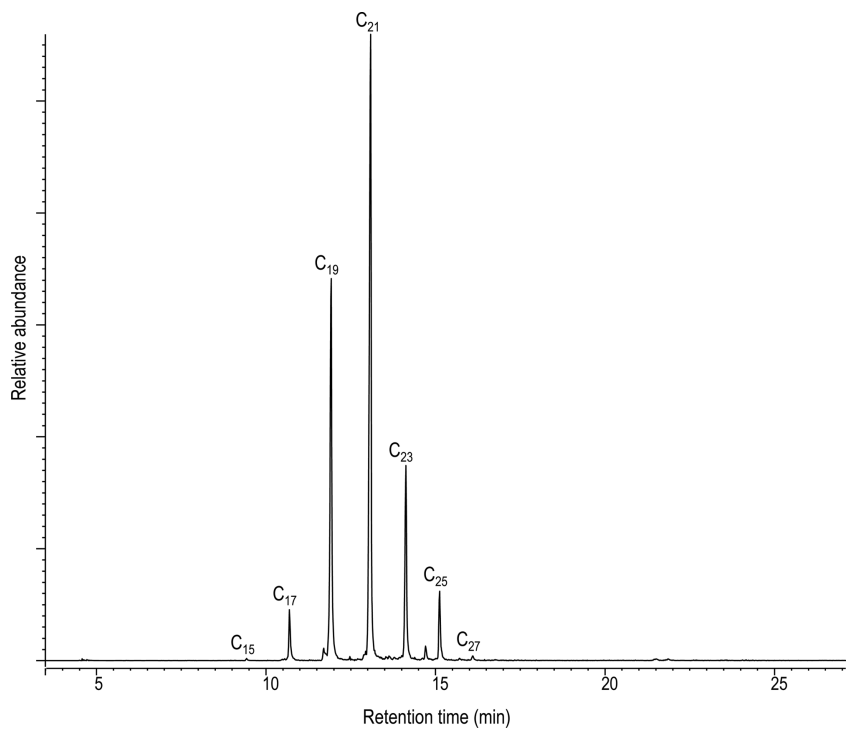

Figure 8. Single ion chromatogram $(m / z$ 268) showing the distribution of the series of $n$-alkylresorcinols (as TMS ethers) identified in the extracts of wheat bran. $\mathrm{C}_{n}$ indicates the carbon length of the alkyl chain.

5- $n$-alkylresorcinols present among the lipids of wheat bran. The 5- $n$-alkylresorcinols ranged from 5-n-pentadecyl $\left(\mathrm{C}_{15}\right)$ to 5-n-heptacosylresorcinol $\left(\mathrm{C}_{27}\right)$, with the sole occurrence of the odd carbon atom-numbered homologues, and with 5- $n$-heneicosylresorcinol $\left(\mathrm{C}_{21}, \mathrm{XI}\right)$ being the most abundant one $(1140 \mathrm{mg} / \mathrm{kg})$, followed by 5 - $n$-nonadecylresorcinol $(660 \mathrm{mg} / \mathrm{kg})$. Alkylresorcinols are known to occur in cereal grains and their occurrence in wheat bran has been widely reported. ${ }^{9,11-14,25}$ The distribution of alkylresorcinols identified is similar to that found in previous works, ${ }^{9,11-14,25}$ although in the present work we have extended the series of identified alkylresorcinols up to $\mathrm{C}_{27}$.

Possible Uses and Benefits of Wheat Bran Lipids. The study shown here indicates that wheat bran is a promising source of phytochemicals, such as fatty acids, triglycerides, phytosterols, and alkylresorcinols. These compounds have a wide range of nutraceutical, pharmaceutical, and cosmetic properties and are also of interest for other industrial sectors. The particularly high content of free fatty acids (40\%) and acylglycerols (40\%) in wheat bran extracts makes this material an interesting feedstock for biodiesel production, which is nowadays essentially produced from oil seed crops. ${ }^{26}$ The potential use of cereal brans, such as rice bran, as useful feedstocks for biodiesel production, has recently being reported, ${ }^{27}$ although there could be some considerations if the material used in animal diets are diverted to fuel production. Among the fatty acids, wheat bran also contains important amounts of linoleic acid, an essential unsaturated omega- 6 fatty acid that must be consumed for proper health and is of interest for the food industry. Moreover, linoleic acid is also used in pharmaceutical and cosmetic products and is considered to influence the metabolic processes in the skin and to promote the activity of vitamins $\mathrm{A}$ and $\mathrm{E}$ and recovery barrier properties of stratum corneum. ${ }^{28}$ On the other hand, phytosterols, which are also present in important amounts in wheat bran, when used as functional ingredients in foods, reduce blood cholesterol levels by interfering with intestinal cholesterol absorption. $^{29,30}$ The efficacy of phytosterols as cholesterollowering agents have been shown when incorporated into fat spreads as well as other food matrices. In addition, phytosterols have been combined with other beneficial dietary components to enhance their effect on risk factors of cardiovascular disease. Phytosterols appear not only to play an important role in the regulation of cardiovascular disease, but also to exhibit anticancer properties. ${ }^{30}$ Hence, phytosterols, especially sitosterol, are suggested to have a protective effect against the most common cancers in the developed countries including colon, prostate, and breast. ${ }^{12}$ In addition, sterol ferulates present anti-inflammatory effects and are also effective antitumor-promoters. ${ }^{31}$ Finally, the important amounts of alkylresorcinols present in wheat bran are of special value since they are involved in multiple biological activities, including antimicrobial, ${ }^{32}$ antiparasitic, ${ }^{33,34}$ antioxidant, ${ }^{13,14,35}$ and antimutagenic activities. ${ }^{9,11,12,36}$

In conclusion, we report a comprehensive description of the chemical composition of lipids in wheat bran that opens up new possibilities for a more complete industrial utilization of this side-stream in the context of a wheat bran biorefinery. Due to the large amounts produced annually worldwide, wheat bran can be viewed as an unexploited and promising source of highly valuable phytochemicals with potential health benefits and biological activities. Variations in the chemical composition of the lipids, however, can be expected to occur among different wheat bran samples from differences in wheat cultivars and milling procedures; the screening and analysis of additional wheat bran samples are therefore needed in order to evaluate the divergences in the composition and content of lipids among samples from different sources.

\section{AUTHOR INFORMATION}

\section{Corresponding Author}

*Tel: +34-95-4624711; Fax: +34-95-4624002; E-mail: delrio@ irnase.csic.es.

\section{Funding}

This study has been funded by the Spanish project AGL201125379 and the EU-project LIGNODECO (KBBE-244362). Pepijn Prinsen thanks the Spanish Ministry of Science and Innovation for a FPI fellowship.

\section{Notes}

The authors declare no competing financial interest.

\section{ACKNOWLEDGMENTS}

We thank Jorge Rencoret for technical assistance in the GC-MS analyses.

\section{REFERENCES}

(1) Shewry, P. R.; Piironen, V.; Lampi, A.; Edelmann, M.; Kariluoto, S.; Nurmi, T.; Fernandez-Orozco, R.; Ravel, C.; Charmet, G.; Andersson, A. A. M.; Aman, P.; Boros, D.; Gebruers, K.; Dornez, E.; Courtin, C. M.; Delcour, J. A.; Rakszegi, M.; Bedo, Z.; Ward, J. L. The HEALTHGRAIN Wheat Diversity Screen: Effects of Genotype and Environment on Phytochemicals and Dietary Fiber Components. J. Agric. Food Chem. 2010, 58, 9291-9298.

(2) Fardet, A. New Hypotheses for the Health-Protective Mechanisms of Whole-Grain Cereals: What Is beyond Fibre? Nutr. Res. Rev. 2010, 23, 65-134.

(3) Reisinger, M.; Tirpanalan, Ö.; Prückler, M.; Huber, F.; Kneifel, W.; Novalin, S. Wheat Bran Biorefinery-A Detailed Investigation on Hydrothermal and Enzymatic Treatment. Bioresour. Technol. 2013, 144, 179-185.

(4) Swennen, K.; Courtin, C. M.; Lindemans, G. C. J. E.; Delcour, J. A. Large-Scale Production and Characterisation of Wheat Bran Arabinoxylooligosaccharides. J. Sci. Food Agric. 2006, 86, 1722-1731.

(5) Mandalari, G.; Faulds, C. G.; Sancho, A. I.; Saija, A.; Bisignano, G.; LoCurto, R; Waldron, K. W. Fractionation and Characterisation of 
Arabinoxylans from Brewers' Spent Grain and Wheat Bran. J. Cereal Sci. 2005, 42, 205-212.

(6) Anderson, J. W. Whole Grains and Coronary Heart Disease: The Whole Kernel of Truth. Am. J. Clin. Nutr. 2004, 80, 1459-1460.

(7) Montonen, J.; Knekt, P.; Jarvinen, R.; Aromaa, A.; Reunanen, A. Whole-Grain and Fiber Intake and the Incidence of Type 2 Diabetes. Am. J. Clin. Nutr. 2003, 77, 622-629.

(8) Landberg, R.; Kamal-Eldin, A.; Andersson, S.; Johansson, J.; Zhang, J.; Hallmans, G.; Aaman, P. Reproducibility of Plasma Alkylresorcinols during a 6-Week Rye Intervention Study in Men with Prostate Cancer. J. Nutr. 2009, 139, 975-980.

(9) Liu, L.; Winter, K. M.; Stevenson, L.; Morris, C.; Leach, D. N. Wheat Bran Lipophilic Compounds with in Vitro Anticancer Effects. Food Chem. 2012, 130, 156-164.

(10) Sang, S.; Ju, J.; Lambert, J. D.; Lin, Y.; Hong, J.; Bose, M.; Wang, S.; Bai, N.; He, K.; Reddy, B. S.; Ho, C. T.; Li, F.; Yang, C. S. Wheat Bran Oil and Its Fractions Inhibit Human Colon Cancer Cell Growth and Intestinal Tumorigenesis in $\mathrm{Apc}(\mathrm{min} /+)$ Mice. J. Agric. Food Chem. 2006, 54, 9792-9797.

(11) Zhu, Y.; Conklin, D. R.; Chen, H.; Wang, L.; Sang, S. 5Alk(en)ylresorcinols as the Major Active Components in Wheat Bran Inhibit Human Colon Cancer Cell Growth. Bioorg. Med. Chem. 2011, 19, 3973-3982.

(12) Iwatsuki, K.; Akihisa, T.; Tokuda, H.; Ukiya, M.; Higashihara, H.; Mukainaka, T.; Iizuka, M.; Hayashi, Y.; Kimura, Y.; Nishino, H. Sterol Ferulates, Sterols, And 5-Alk(en)ylresorcinols from Wheat, Rye, And Corn Bran Oils and Their Inhibitory Effects on Epstein-Barr Virus Activation. J. Agric. Food Chem. 2003, 51, 6683-6688.

(13) Gunenc, A.; HadiNezhad, M.; Tamburic-Ilincic, L.; Mayer, P. M.; Hosseinian, F. Effects of Region and Cultivar on Alkylresorcinols Content and Composition in Wheat Bran and Their Antioxidant Activity. J. Cereal Sci. 2013, 57, 405-410.

(14) Gunenc, A.; Tavakoli, H.; Setharaman, K.; Mayer, P. M.; Fairbanks, D.; Hosseinian, F. Stability and Antioxidant Activity of Alkylresorcinols in Breads Enriched with Hard and Soft Wheat Brans. Food Res. Int. 2013, 51, 571-578.

(15) Gutiérrez, A.; del Río, J. C.; González-Vila, F. J.; Martín, F. Analysis of Lipophilic Extractives from Wood and Pitch Deposits by Solid-Phase Extraction and Gas Chromatography. J. Chromatogr. A 1998, 823, 449-455.

(16) Tappi Test Methods 2004-2005; Tappi Press: Norcoss, GA, 2004.

(17) Browning, B. L. Methods of Wood Chemistry, Vol. II; WileyInterscience Publishers: New York, 1967.

(18) Dutta, P.; Appelqvist, L. -Å. Saturated Sterols (Stanols) In Unhydrogenated and Hydrogenated Edible Vegetable Oils and in Cereal Lipids. J. Sci. Food Agric. 1996, 71, 383-391.

(19) del Río, J. C.; Prinsen, P.; Gutiérrez, A. Chemical Composition of Lipids in Breweŕs Spent Grain: A Promising Source of Valuable Phytochemicals. J. Cereal Sci. 2013, 58, 248-254.

(20) del Río, J. C.; Prinsen, P.; Gutiérrez, A. A Comprehensive Characterization of Lipids in Wheat Straw. J. Agric. Food Chem. 2013, 61, 1904-1913.

(21) Gutiérrez, A.; del Río, J. C. Gas Chromatography/Mass Spectrometry Demonstration of Steryl Glycosides in Eucalypt Wood, Kraft Pulp and Process Liquids. Rapid Commun. Mass Spectrom. 2001, 15, 2515-2520.

(22) Esche, R.; Scholz, B.; Engel, K. -H. Online LC-GC Analysis of Free Sterols/Stanols and Intact Steryl/Stanyl Esters in Cereals. J. Agric. Food Chem. 2013, 61, 10932-10939.

(23) Evershed, R. P.; Spooner, N.; Prescott, M. C.; Goad, L. J. Isolation and Characterisation of Intact Steryl Ferulates from Seeds. J. Chromatogr. A 1988, 440, 23-35.

(24) Zarnowski, R.; Suzuki, Y.; Yamaguchi, I. Alkylresorcinols in Barley (Hordeum vulgare L. distichon) Grains. Z. Naturforsch. 2002, $57 c, 57-62$.

(25) Athukorala, Y.; Hosseinian, F. S.; Mazza, G. Extraction and Fractionation of Alkylresorcinols from Triticale Bran by Two-Step
Supercritical Carbon Dioxide. LWT-Food Sci. Technol. 2010, 43, 660-665.

(26) Singh Nigam, P.; Singh, A. Production of Liquid Biofuels from Renewable Resources. Prog. Energ. Combust. Sci. 2011, 37, 52-68.

(27) Zhang, Y.; Wong, W. -T.; Yung, K. -F. One-Step Production of Biodiesel from Rice Bran Oil Catalyzed by Chlorosulfonic Acid Modified Zirconia via Simultaneous Esterification and Transesterification. . Bioresour. Technol. 2013, 147, 59-64.

(28) Huang, F. C.; Ju, Y. H.; Chiang, J. C. Gamma-Linolenic AcidRich Triacylglycerols Derived from Borage Oil via Lipase-Catalyzed Reactions. J. Am. Oil Chem. Soc. 1999, 76, 833-837.

(29) Quílez, J.; García-Lorda, P.; Salas-Salvadó, J. Potential Uses and Benefits of Phytosterols in Diet: Present Situation and Future Directions. Clin. Nutr. 2003, 22, 343-351.

(30) Jones, P. J.; AbuMweis, S. S. Phytosterols as Functional Food Ingredients: Linkages to Cardiovascular Disease and Cancer. Curr. Opin. Clin. Nutr. Metab. Care 2009, 12, 147-51.

(31) Akihisa, T.; Yasukawa, K.; Yamaura, M.; Ukiya, M.; Kimura, Y.; Shimizu, N.; Arai, K. Triterpene Alcohol and Sterol Ferulates from Rice Bran and Their Anti-Inflammatory Effects. J. Agric. Food Chem. 2000, 48, 2313-2319.

(32) Reiss, J. Influence of Alkylresorcinols from Rye and Related Compounds on the Growth of Food-Borne Moulds. Cereal Chem. 1989, 66, 491-493.

(33) Kozubek, A.; Tyman, J. H. P. Resorcinol Lipids, The Natural Non-Isoprenoid Phenolic Amphiphiles and Their Biological Activity. Chem. Rev. 1999, 99, 1-25.

(34) Suresh, M.; Raj, R. K. Cardol: Antifilarial Principle from Anacardium occidentale. Curr. Sci. 1990, 59, 477-479.

(35) Hładyszowski, J.; Zubik, L.; Kozubek, A. Quantum Mechanical and Experimental Oxidation Studies of Pentadecylresorcinol, Olivetol, Orcinol and Resorcinol. Free Radical Res. 1998, 28, 359-368.

(36) Gasiorowski, K.; Brokos, B.; Kulma, A.; Ogorzałek, A.; Skórkowska, K. Impact of Four Antimutagens on Apoptosis in Genotoxically Damaged Lymphocytes in Vitro. Cell. Mol. Biol. Lett. 2001, 6, 649-675. 